\title{
EDITORIAL
}

\section{Sound in space}

There has been an extraordinary amount of interest in sound spatialisation in recent years. The volume of work in this area has pushed many international organisations to feature sound spatialisation as a theme for conferences and publications, and Organised Sound is probably overdue in having a thematic issue based upon aspects of sound in space. This issue of Organised Sound contains many different views of space. We have included articles about spatialisation techniques, our understanding of sound spatialisation, composition, performance and spaces inside music as well as the spaces and environments where music can exist, including virtual spaces.

This Editorial will concentrate largely upon just one of these issues. I am particularly pleased to write an Editorial for the first issue of Organised Sound to feature an article based upon a perceptual approach to the composition and spatialisation of sound. I have had the pleasure of being associated with this work and have seen it develop over the last few years into an issue that I hope will be of significant interest to composers and engineers in the future. I will expand on this approach by way of an introduction to David Worrall's paper, 'Space in sound: sound of space', as the paradigm-shift which forms the basis of his article is complex and may be quite new to many readers.

When I listen to surround-sound or three-dimensional (3D) sound systems, I have to admit that there are only rare occasions when I am convinced that $3 \mathrm{D}$ sound images or 3D movements exist. When they do, the affect is startling but lasts only for a brief moment of time - rarely do I experience any consistent depth of illusion or the semi-immersive audio environment that I expect to be reproduced (particularly, though not exclusively, in concert performances). I do not appear to be alone in this. Research into this perceptual approach suggests that the reasons for this fragility could be twofold: (i) that our approach to spatialised sound reproduction is not always appropriate, and (ii) that our understanding of audio spatial perception is limited.

In a number of sound spatialisation techniques, the method of reproduction is informed in part by theories of perception and psychoacoustics. The new approach suggests that the psychoacoustic theories which underpin current techniques require updating to incorporate more recent developments in perceptual and psychoacoustic research if 3D sound worlds are to be sustained by both reproduction systems and compositions. One aspect of this work has taken models from Gibson (1979), along with other contemporary theories of perception, to seek parallels in the audio domain. Details of this work can be found elsewhere (Lennox, Myatt and Vaughan 1999), but in short it suggests that we need to adopt a votive, holistic approach to inform our sound spatialisation techniques, based upon models of perception which include active hypothesis testing.

This suggests that sound locations cannot be perceived correctly unless one considers all properties of a sound when composing, encoding and reproducing sounds in space, e.g. where does the sound exist, what is its environment, how large is the sounding object, which way is it facing with respect to the listener, what do the sonic characteristics of the sound communicate to our perceptual system about its location? All these parameters need to be considered in addition to a sound's distance, angle of elevation and rotation from the listener. We do not possess the ability to identify distances absolutely from aural information alone; there are no Euclidean units of measurement that can be communicated via our auditory perception mechanisms.

This paradigm promotes a perception-centred approach to sound spatialisation based upon the perception of objects in environments. It seems quite likely that we do not have any perceptual mechanisms which enable us to hear very complex, abstract sound trajectories and certainly not if they are presented to us without context or frames-of-reference in the audio domain. This implies that it may not be appropriate to describe sound locations using a Euclidean geometric space if they are intended to be perceived by a system that cannot interpret the parameters of Euclidean space. 'Perceptual space' has been proposed as a term to describe the space that sounds inhabit where their locations are described from the perceiver's viewpoint (David Worrall 
describes a similar space which he refers to as '3space').

David Worrall considers the implication of these theories for composers and compositional thinking. This paradigm also suggests considerable engineering challenges. It seems that no one sound spatialisation technique is likely to be capable of reproducing perceptual space-based music or sound environments; at present, a hybrid reproduction technology seems to offer the most appropriate solution, but many, many challenges remain in the design of appropriate encoding systems and reproduction technologies.

This issue of Organised Sound contains articles by some of the leading figures in electroacoustic music about their work with sound and space. In addition to the contribution from David Worrall, Jonty Harrison, who is known throughout the world for his work with the BEAST concert performance system, reveals some of the techniques and theories that define his approach to electroacoustic sound reproduction in the concert hall. Barry Truax has also had a longterm commitment to sounds, spaces and environments through his composition and writing, and we are delighted to be able to welcome him back to the pages of Organised Sound. Simon Emmerson writes about how sound can evoke a sense of being and place and discusses how this may be strongly related to our visual experience. Anna Maria Harley considers twentieth-century instrumental works that feature spatial concerns, and Minni Ang et al. take us into digital space in a discussion of Malaysian music on the World Wide Web.

In addition, David Malham provides a Tutorial Article that describes a number of current sound spatialisation techniques, and Ville Pulkki focuses upon the creation and generation of generic sound spaces for multichannel loudspeaker systems.

This is the first issue of Organised Sound to feature a reduced Announcements section as part of the journal's back matter. We have a significant lead-time on each issue of Organised Sound and it is becoming increasingly difficult for us to publish announcements of events before they take place. The Editors were concerned that the community might lose a vehicle for communication by this action, but we are reassured by the level of activity on the computer networks and, in particular, the debates that are enabled by groups such as sursound and cecdiscuss, along with the commercial groups like the Electronic Music Foundation and IRCAM Forum. We will continue to publish announcements of recordings and products where relevant.

Tony Myatt

(This issue was co-edited by Leigh Landy)

\section{References}

Gibson, J. J. 1979. The Ecological Approach to Visual Perception. Boston: Houghton Mifflin.

Lennox, P. P., Myatt, A., and Vaughan, J. M. 1999. From surround to true 3-D. Proc. of the Audio Engineering Society 16th Int. Conf. on Spatial Sound Reproduction. 